
\title{
ECJSE
}

Makale / Research Paper

\section{Kaynak Prosesi Sonucu Oluşan Kalıntı Gerilmelere Kaynak Teli Isıl Genleşme Katsayısının Etkisi}

\author{
Murat ASLAN $^{1}$, Mete KALYONCU ${ }^{2}$ \\ ${ }^{1}$ MPG Makine İmalat Sanayi ve Ticaret A.Ş/ Selçuk Üniversitesi Fen Bilimleri Enstitüsü \\ ${ }^{2}$ Selçuk Üniversitesi / Mühendislik Fakültesi Makine Mühendisliği \\ ${ }^{1}$ murat_6442@hotmail.com - ${ }^{2}$ mkalyoncu@selcuk.edu.tr
}

\begin{abstract}
Özet: Kaynak teknolojisinde meydana gelen gelişmeler, kaynaklı birleştirmenin imalat sektöründe giderek artan oranda yaygınlaşmasına neden olmuştur. Bu nedenle imalat sektöründe çalışan teknik elemanlar kaynak işleminin tasarım, imalat ve kontrol problemleriyle yoğun olarak uğraşmaktadırlar. Bu çalışmada, kaynak prosesi ile oluşturulmuş bir makine parçasında meydana gelen kalıntı gerilmeler ve bu kalıntı gerilmelerin emniyet ve parça ömrü üzerine etkileri bir analiz programı yardımı ile simule edilerek incelenmiştir. Farklı kaynak teli modelleri oluşturularak kaynak telinin ısıl genleşme katsayısının kaynak prosesi sonucu oluşan kalıntı gerilmeler üzerine etkisi incelenmiştir. Teorik olarak yapılan çalışmada kaynak tellerindeki 1 sıl genleşme katsayısında \%1 - \%3 oranda farklı olmasına karşın kalıntı gerilmelerde \%5 - \%10 arasında farklılıklar oluştuğu gözlemlenmiştir. Bu çalışma ile kaynak telinin yapısal özelliği olan isıl genleşme katsayısının kalıntı gerilmeler üzerinde büyük etkisi olduğu belirlenmiştir. İmalat esnasında kullanılacak kaynak telinin mekanik özelliklerinin yanı sıra ısıl genleşme katsayısının da göz önüne alınarak gerekli hesapların yapılmasının ileride doğabilecek sorunların önüne geçebileceği ön görülmüştür.
\end{abstract}

Anahtar Kelimeler: Kaynak prosesi, 1sıl genleşme katsayısı, kalıntı gerilme analizi.

\section{Affect of Welding Wire Thermal Expansion Coefficient To Residual Stress Occurred Due To Welding Process}

\begin{abstract}
Developments at welding technology caused increasingly rate of welding conjunction in manufacturing sector. Therefore technical personnel employed at manufacturing sector are dealing with intensively design, manufacturing and control problems of welding processes. In this study, residual stress at a machine part composed by welding process and affects of those residual stresses on safety and part life had been analyzed through simulation with assistance of an analysis program. Different welding wire models were composed and affects of coefficient of welding wire thermal expanding on residual stresses occurred due to welding process had been examined. In the study that was performed theoretically, it had been observed that the thermal expanding coefficient at welding wires varied $1 \%-3 \%$ rates but it was $5 \%-10 \%$ at residual stress. It has been determined with this study that thermal expanding coefficient that is structural feature of welding wire had great affect on residual stress. Beside mechanical features of welding wire that will be used during manufacturing process, its thermal expanding coefficient should be considered and so required calculations should be subject to those values; therefore it had been presumed that such measurements may prevent any possible future problems.
\end{abstract}

Keywords: Welding process, thermal expansion coefficient, residual stress analysis. 


\section{Giriş}

Kaynaklı birleştirmenin imalat sektöründe giderek artan oranda yaygınlaşması çalışan teknik elemanlar için kaynak işleminin kontrol problemleriyle yüz yüze kalmasına neden olmuştur. Bu çalışmada bunlar arasında en çok karşılaşılan problem olan kalıntı gerilmeler ve bu gerilmeler sonucun da oluşan yer değiştirmeler incelenmiştir.

Tasarım aşamasında kaynaklı birleştirme tekniği ile üretilmesi düşünülen bir makine parçasında üretime geçilmeden üretim esnasında parça içerisinde oluşabilecek kalıntı gerilmeleri ve bu gerilmelere etki eden ısıl genleşme katsayıları incelenmiştir.

Kalıntı gerilmeler çoğu zaman parça içerisinde istenilmeyen fakat üretimin herhangi bir aşamasında (kaynak işlemi, tornalama, döküm v.b.) farklı nedenlerle oluşan parçadaki iç gerilmelerdir. Kaynaklı birleştirme uygulanacak parçalarda yüksek sıcaklık ve ani ssınma soğuma sonucunda parçanın yüzeyinde ve merkez noktalarında kalıntı gerilmeler oluşmaktadır. Bu gerilmeler parça içerisinde kalıcı olup parça mukavemeti ile doğrudan ilişkilidir. Kalıntı gerilmeler üzerine yapılan çalışmalar iki temel esasa dayanmaktadır [3-14]. Bunlar;

- Kalıntı gerilme mekanizmalarının etki düzeyi,

- Kalıntı gerilmelerin önceden tahmini şeklindedir.

$\mathrm{Bu}$ çalışmada kalıntı gerilmelerin önceden tahmini kısmı ile ilgili teorik bir çalışma yaparak kaynak işlemi esnasında oluşabilecek problemleri önceden tespit edilmeye çalışılmıştır. Çalışmanın temeli parça mekanik özelliklerinden olan ısıl genleşme katsayısının kalıntı gerilmeler üzerine etkilerinin belirlenmesidir. Yapılan bu teorik çalışmada parça modeli bir CAD programı yardımı ile oluşturularak sadece kaynak prosesi için özel olarak hazırlanmış olan SIMUFACT WELDING analiz programı ile kaynak dokusunun analizi yapılmıştır. Hazırlanan CAD modeli özel bir transfer programı ile mesh (ağ) yapısı oluşturularak teorik çalışma için uygun hale getirilmiştir.

Bu çalışmada dört adet farklı kaynak teli modeli ile analizler aynı şartlar altında yapılarak oluşan kalıntı gerilmeler ve yer değiştirmeler incelenmiştir.

\section{Materyal ve Metot}

\subsection{Malzeme}

Tasarımı yapılan iş parçası ST 37 ( S235 - DIN 1.0037 ) alaşımlı çelik malzemeden imal edilmiştir. $\mathrm{Bu}$ malzeme için sıcaklığa bağlı ısıl genleşme katsayısı Şekil 1 de verilmiştir.

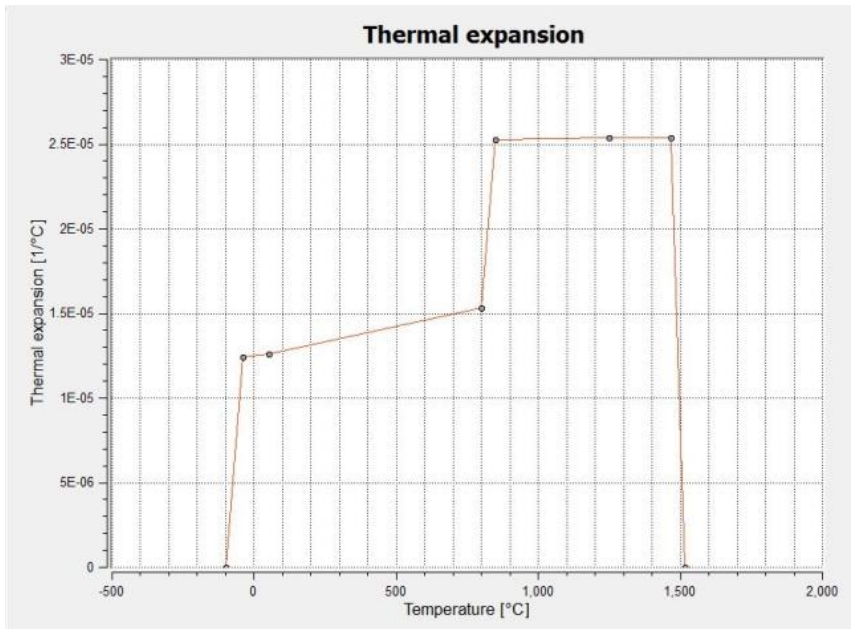

Şekil 1. DIN 1.0037 malzemenin 1sıl genleşme katsayısı 
Kaynak işlemi sırasında kullanılacak kaynak tellerinin 1sıl genleşme katsayıları Tablo 1 de verilmiştir. Burada önemli olan nokta kaynak tellerinin mekanik ve 1sıl bütün değerleri iş parçası (DIN 1.0037) ile aynı olup sadece 1sıl genleşme katsayısı sıcaklığa bağlı değildir. Sabit değerler verilerek analiz yapılmıştır.

Tablo 1. Isıl genleşme katsayıları

\begin{tabular}{|c|c|c|c|c|}
\hline & MODEL 1 & MODEL 2 & MODEL 3 & MODEL 4 \\
\hline TER. GEN. KAT. & $1.25 E-5$ & $1.29 \mathrm{E}-5$ & $1.33 \mathrm{E}-5$ & $1.37 \mathrm{E}-5$ \\
\hline
\end{tabular}

Malzeme mekanik özelliklerinin hemen hepsi sıcaklığa bağlı olarak değişmektedir. Uygun bir analiz modeli oluşturabilmek için bu değerlerin biliniyor olması gerekmektedir. Kaynak işlemi esnasında 1sıl değerlerde değişmekte olup 1sı iletim katsayıları da sicaklığa bağlı olarak değişmektedir. $\mathrm{Bu}$ değerler kütüphaneden eklenerek oluşturulmuştur. Parça ile dış ortam sıcaklığından dolayı olan taşınım durumunda ise referans sıcaklık olarak 20 derece ortam ile ve 1s1 transfer katsayısı ise $12 \mathrm{~W} / \mathrm{m}^{\wedge} 2 \mathrm{~K}$ olarak kabul edilmiştir. Aynı zamanda emisyon oranı 0.6 ve temas noktaları arasındaki taşınım $500 \mathrm{~W} / \mathrm{m}^{\wedge} 2 \mathrm{~K}$ olarak kabul edilmiştir.

\subsection{Kullanılan Programlar}

$\mathrm{Bu}$ çalışmada CAD modelini oluşturabilmek için kullanılan program Siemens Unigraphics NX9 olup tüm dünyada uzay, havacılık, otomobil ve sanayinin her alanında kullanılan saygınlığını kazanmış bir CAD - CAM - CAE programıdır.

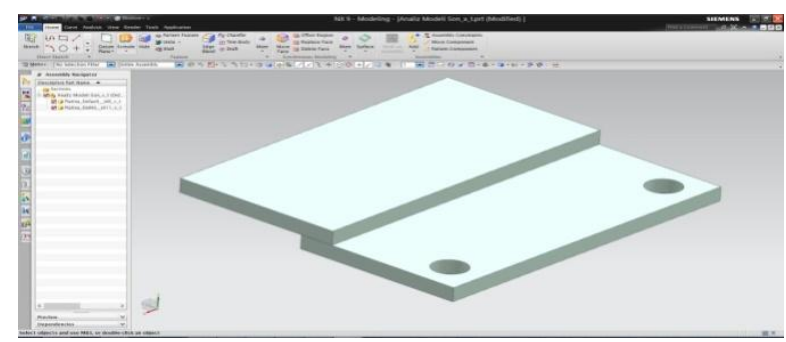

Şekil 2. Analiz CAD modeli

Oluşturulan CAD modelini (Şekil 2) analiz programında açabilmek için belirli bir formata getirmek gerekmektedir. Kullanılan analiz programı mesh tabanlı çalışan bir MSC Software yazılımı olduğu için CAD modeli Simlab programı aracılığı ile mesh yapıya getirilerek programa tanıtılmıştır (Şekil $3)$.

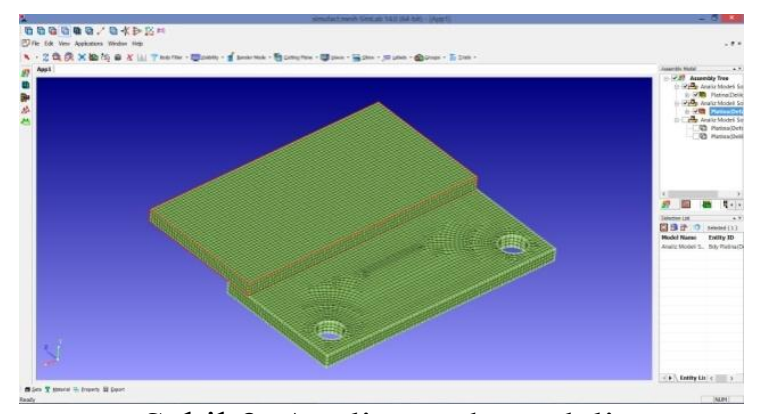

Şekil 3. Analiz mesh modeli

Simufact welding analiz programı kaynak işlemi için özel olarak geliştirilmiş bir MSC Software ürünüdür. Geniş kütüphanesi sayesinde çok fazla malzemenin kaynak işlemi sonrası oluşan deformasyonlarının incelenmesine olanak sağlamaktadır (Şekil 4). 


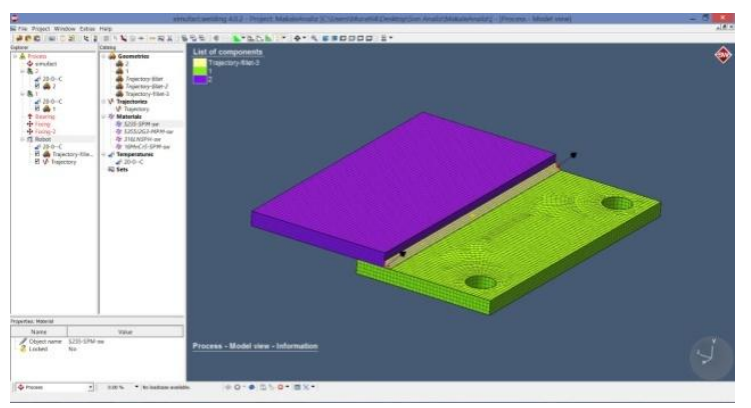

Şekil 4. Analiz CAE modeli

\subsection{Teorik Uygulama}

Hesaplama:

Parçalar üzerinde oluşan kalıntı gerilmeler kaynak işlemi esnasında malzeme dokusunda meydana gelen değişmeler neticesinde ortaya çıkan yüksek enerjili kenar dislokasyonlarının bir sonucudur. Kalıntı gerilmelerin giderilmesi için çeşitli yöntemler uygulanmaktadır. Isııl işlem (Şekil 5), titreşimle gerilim giderme (Şekil 6) hepsinin amacı bu yüksek enerjili dislokasyonların enerjisini düşürerek kararlı hale gelmelerini sağlamaktır.

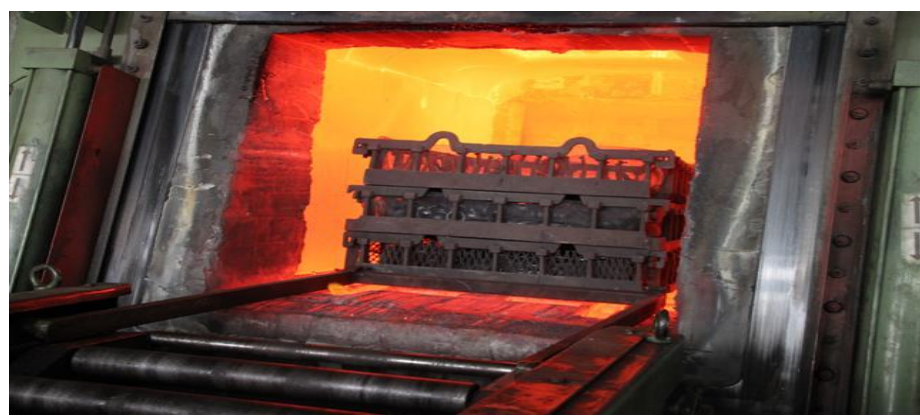

Şekil 5. Isıl işlem ile gerilim giderme

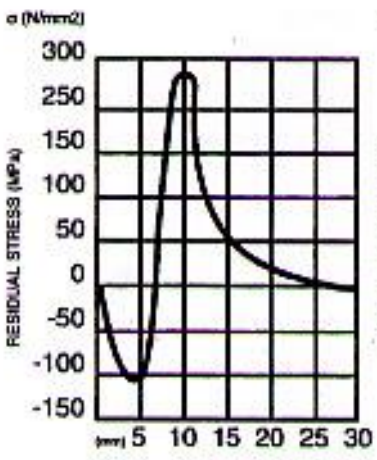

Before Stress Relief (Stresses Unequalized)

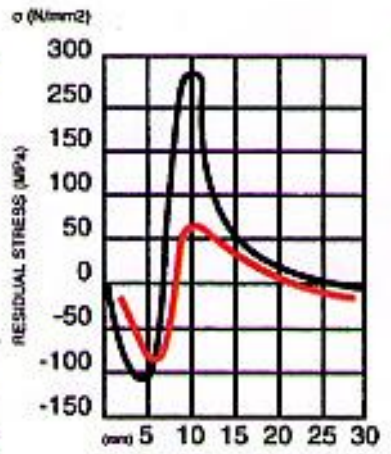

After Vibratory Stress Relief (Equilibrium Restored)

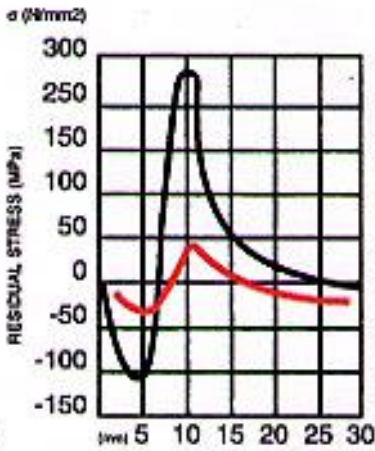

After Thermal Stress Relief (Equilibrium Restored)

Şekil 6. Titreşim ile gerilim giderme

Kalıntı gerilmelerin mikro mekanizması incelendiğinde gerilmelerin oluşmasındaki en önemli nedenin dislokasyon sayısındaki değişim olduğu görülmektedir. Plastik deformasyonların etkisi sonucunda bazı dislokasyonlar kararlı pozisyonlarında dururken, bazı dislokasyonlar ise yüksek enerjili olarak kararsız durumda dururlar. $\mathrm{Bu}$ durum malzemede kalıntı gerilmelere neden olur. $\mathrm{Bu}$ kararsız dislokasyonların etrafındaki gerilmeler ise;

$\sigma=\left(\frac{E}{1-v}\right) \frac{\Delta}{L}$ 
ifadesi ile hesaplanabilir. Fakat bu hesaplama her zaman doğru sonuçlar vermeyebilir. Çünkü elastisitemodülü ve poisson oranı sıcaklığa bağlı olarak değişen değerlerdir. Aynı zamanda kalıntı gerilmeyi oluşturan 3 temel unsur vardır. Bunlar;

$\sigma y=\sigma f+\sigma \Theta+\sigma p$

formülü ile ifade edilmiştir. Burada, $\sigma f$; kesme kuvvetinin neden olduğu kalıntı gerilme, $\sigma$; sıcaklığın neden olduğu kalıntı gerilme, $\sigma$; yüzey katmanındaki faz dönüşümünün neden olduğu kalıntı gerilmedir. Hal böyle olunca doğru bir kalıntı gerilme hesaplanması oldukça zor duruma gelmiştir.

Yapılan deneyler ve ölçümler sonucunda bu değerlerin büyük bir kısmı toplanarak her bir sıcaklık değeri için sonlu elemanlar modeli oluşturulmuş ve kullanıcıların hizmetine analiz programları aracılığı ile sunulmuştur. Teorik çalışmamız da hızlı bir şekilde malzeme üzerinde oluşan kalıntı gerilmeleri en yakın değerleriyle hesaplaması amaçlanmaktadır.

\section{Analiz Modelinin Oluşturulması:}

Mesh yapısı oluşturulmuş model için uygulanması gereken sınır şartları vardır. Kaynak prosesi kendi içerisin de çok karışık bir işlem olduğu için çok farklı kabuller ve en uygun şartlar sunulmalidir.

Bu program için öncelikle kaynak hızı ve kaynak dolgusunun belirlenmesi gerekmektedir. Program kaynak işlemini robot yapıyormuş gibi düşünerek yapmaktadır. Kaynak hızı 20 mm/s olarak kabul edilmiştir. Dış ortam şartları ise Şekil 7 de ki gibi alınmıştır.

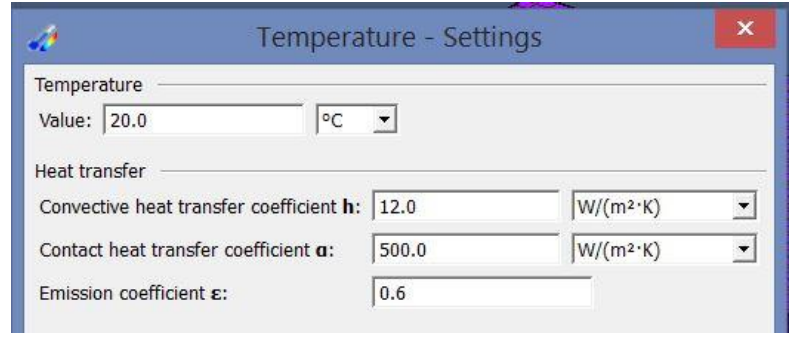

Şekil 7. Dış ortam sınır şartları

Programın anlaması için belirli bir kaynak noktası parametreleri vardır. Bu değerler çeşitli yöntemlerle bulunmuş ve Şekil 8 de belirtilmiştir.

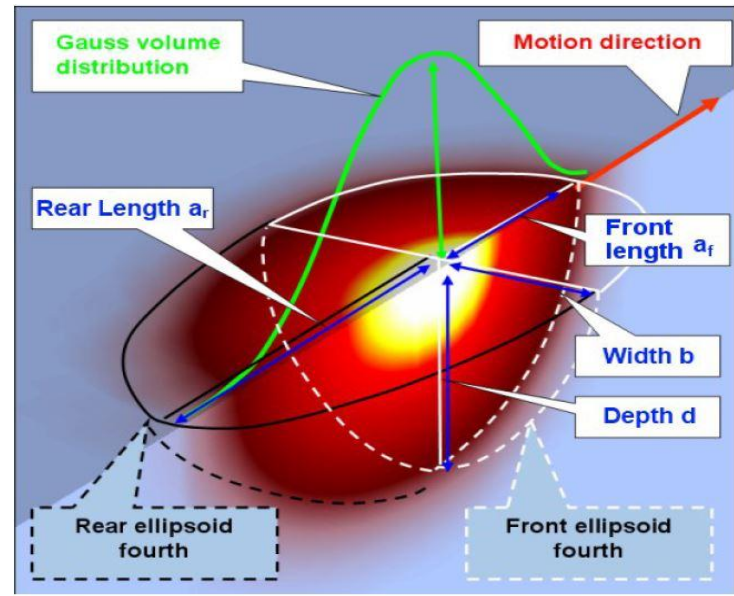

Şekil 8. Kaynak dokusu ölçüleri 
$\mathrm{Bu}$ değerler nizami ve eksiksiz bir şekilde programa girildiği zaman oluşan kaynak dokusu Şekil 9 da ki gibidir.

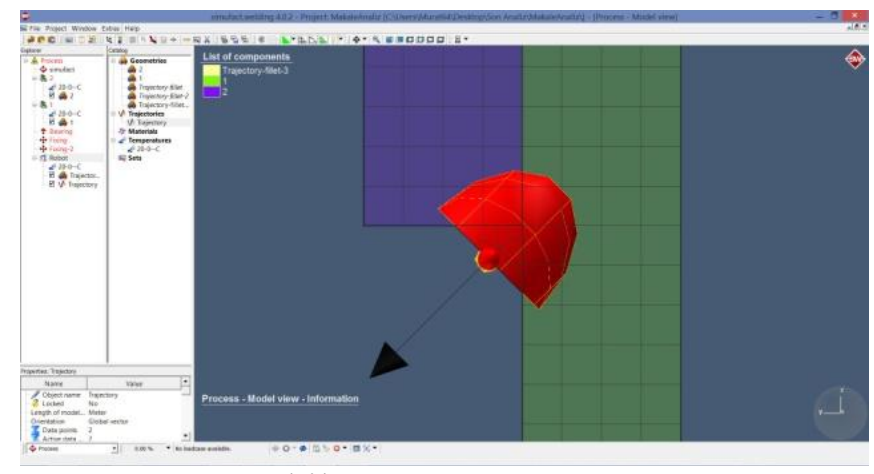

Şekil 9. Kaynak dokusu

Başlangıç ve bitiş değerleri de girildikten sonra prosessin süresi tayin edilmelidir. Bu analizler için prosesin süresini $10 \mathrm{~s}^{\prime}$ de kaynak işlemi bitiyormuş ve $120 \mathrm{~s}^{\prime}$ de parçaların soğuma işlemi tamamlanıyormuş gibi düşünülerek prosesin süresi belirlenmiştir. Aynı zamanda analizin her bir noktası için sürtünme değerleri ihmal edilmiştir.

\section{3- Analiz Sonuçları ve Tartışma}

Analiz modelleri için sonuçlar aşağıdaki şekillerde görülmektedir.

\subsection{Model 1 İçin Analiz Sonuçları}

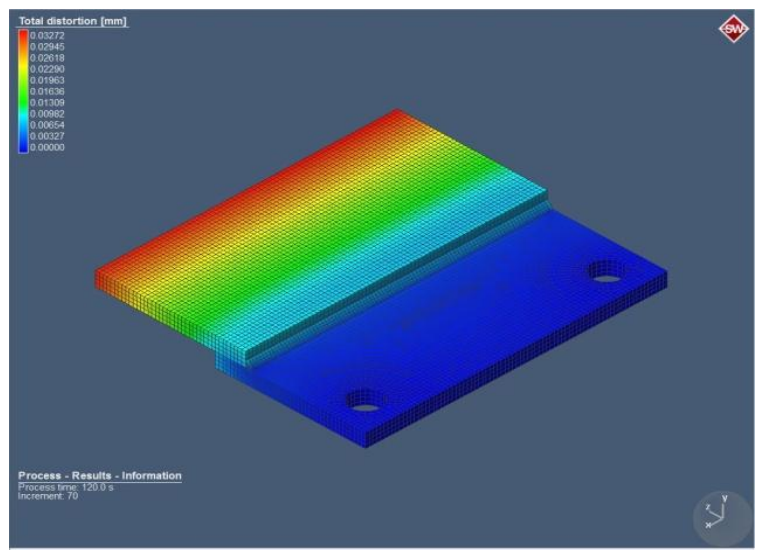

Şekil 10. Model 1 için yer değiştirme

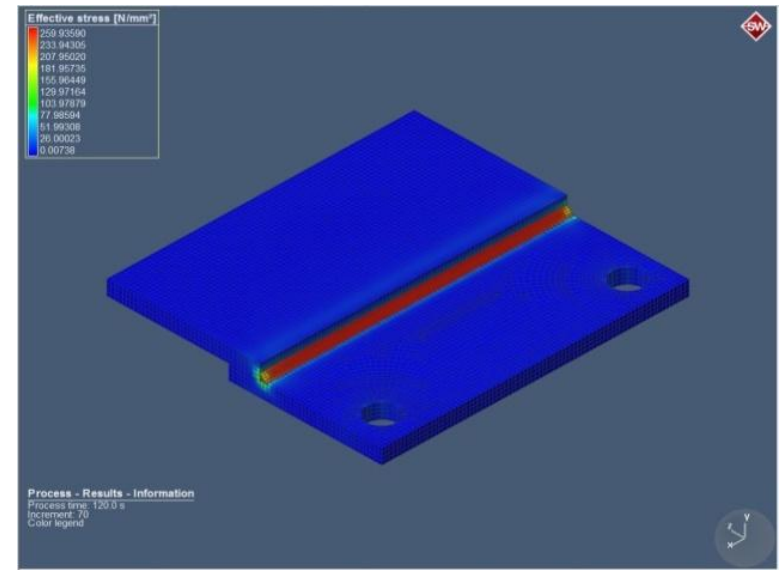

Şekil 11. Model 1 için gerilme 


\subsection{Model 2 İçin Analiz Sonuçları}

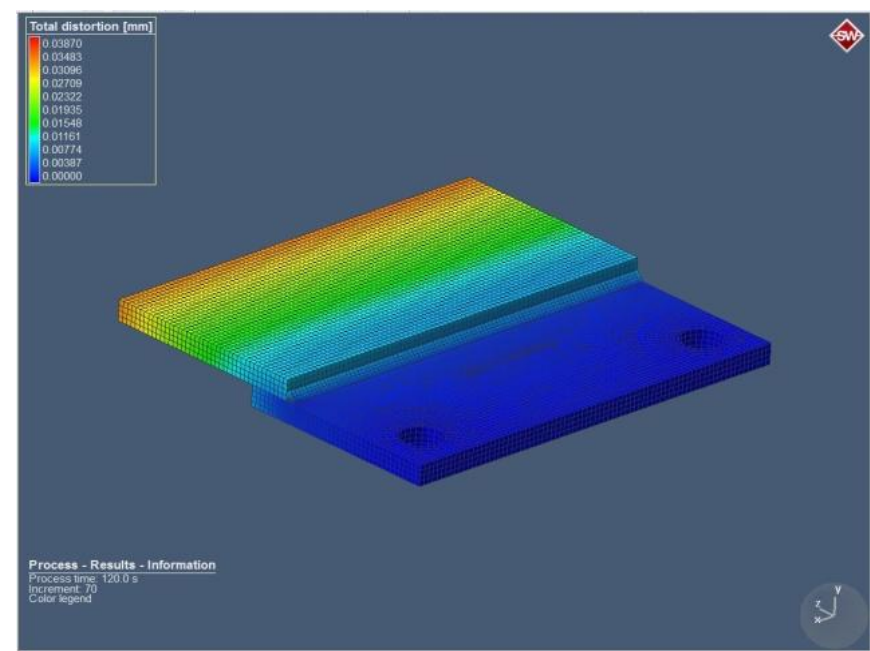

Şekil 12. Model 2 için yer değiştirme

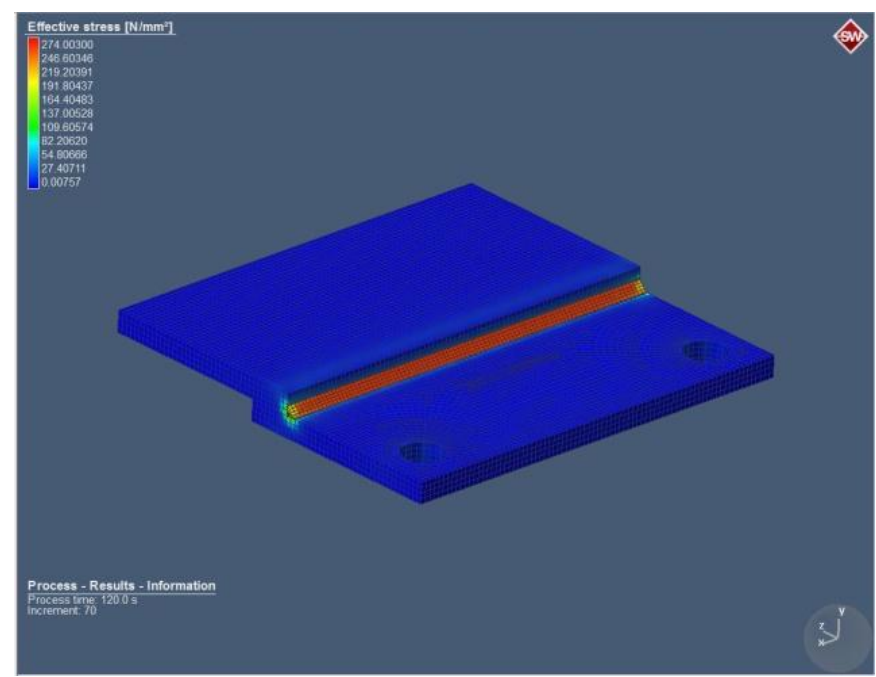

Şekil 13. Model 2 için gerilme

\subsection{Model 3 İçin Analiz Sonuçları}

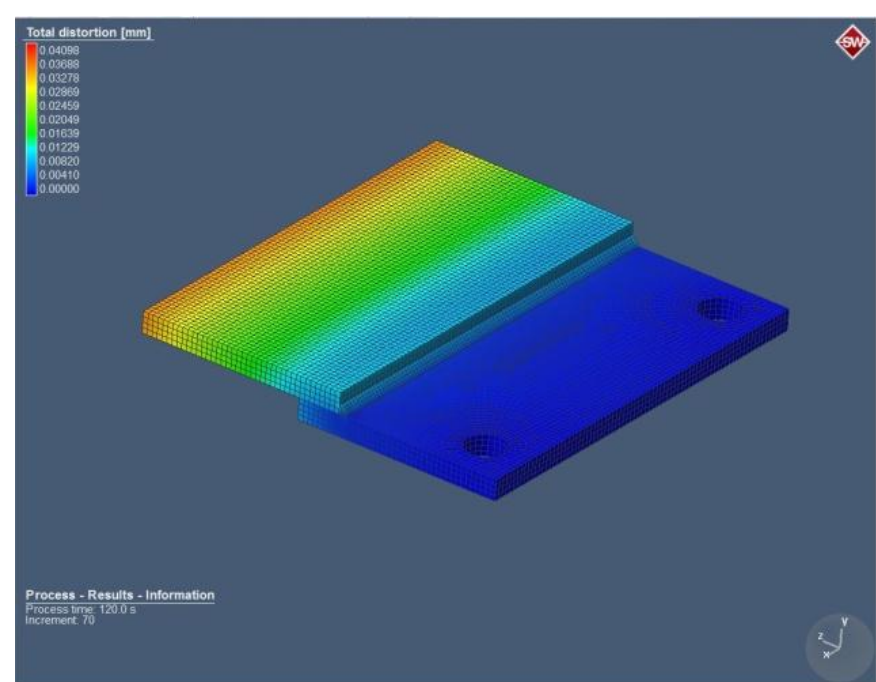

Şekil 14. Model 3 için yer değiştirme 


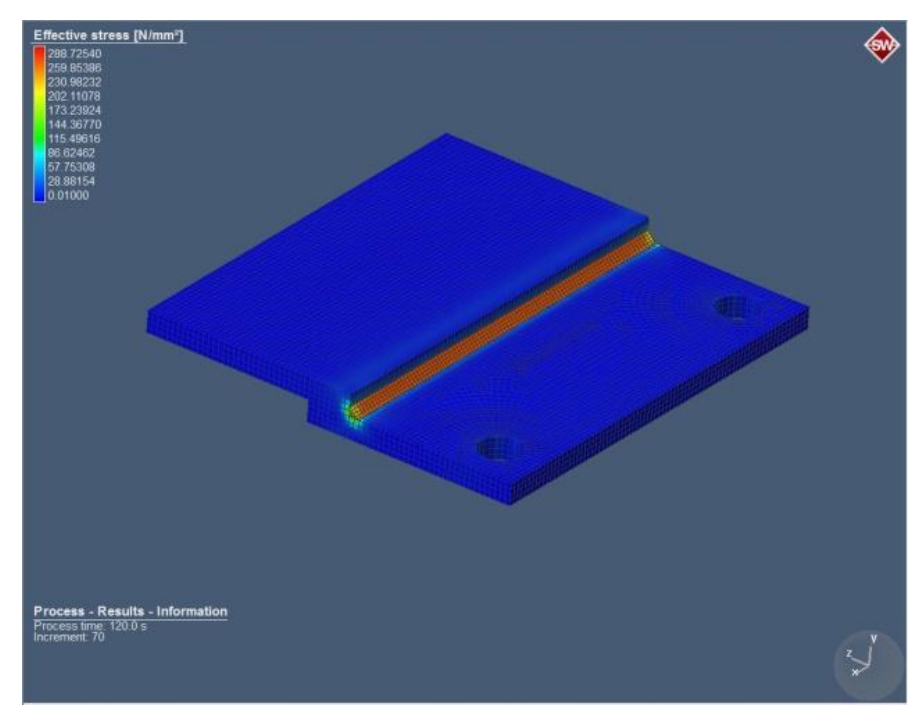

Şekil 15. Model 3 için gerilme

\subsection{Model 4 İçin Analiz Sonuçları}

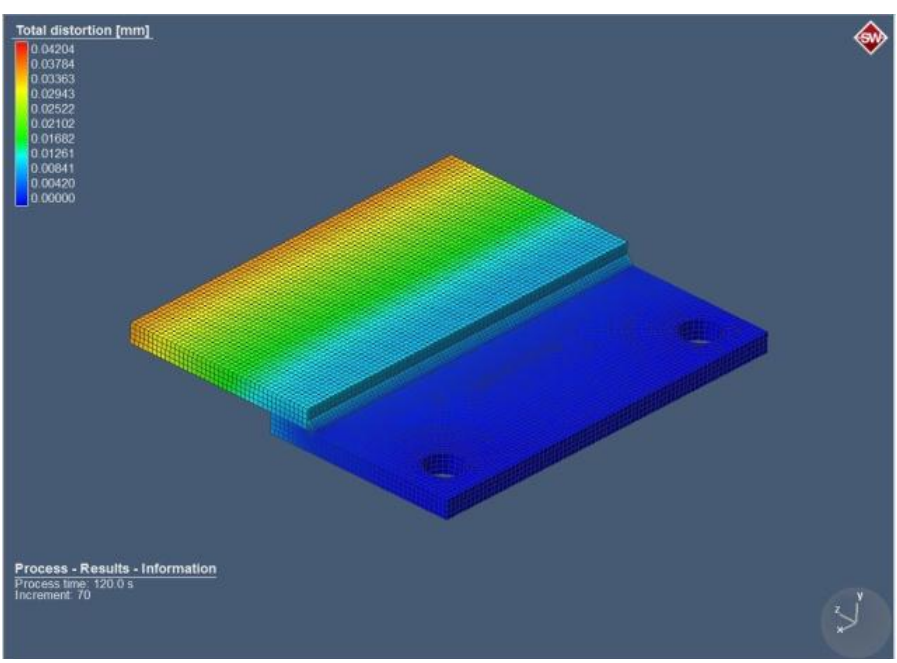

Şekil 16. Model 4 için yer değiştirme

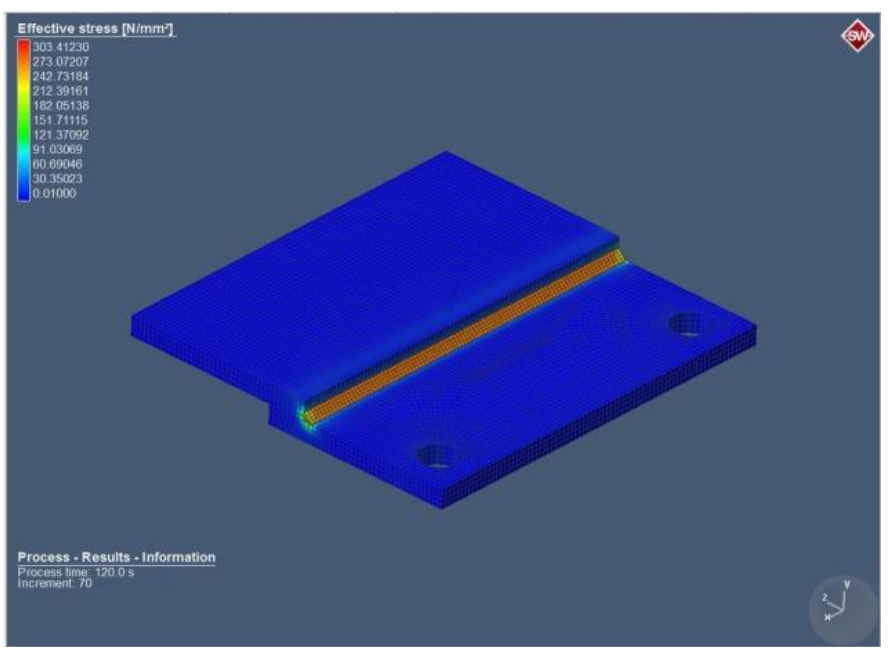

Şekil 17. Model 4 için gerilme 


\section{5 - Tartışma}

Tablo 2. Modeller için analiz sonuçları

\begin{tabular}{|l|c|c|c|c|}
\hline & MODEL 1 & MODEL 2 & MODEL 3 & MODEL 4 \\
\hline YER DEĞİŞTİRME $(\mathrm{mm})$ & 0,03272 & 0,03870 & 0,04098 & 0,04204 \\
\hline GERİME (Mpa) & 259,93590 & 274,00300 & 288,72540 & 303,41230 \\
\hline TER. GEN. KAT. (1/C E-5) & $1.25 \mathrm{E}-5$ & $1.29 \mathrm{E}-5$ & $1.33 \mathrm{E}-5$ & $1.37 \mathrm{E}-5$ \\
\hline
\end{tabular}

Analiz işlemi sonrasında elde edilen sonuçlar Tablo 2 de verilmiştir. Her bir model için $120 \mathrm{~s}$ sonunda gerilme ve çarpılma değerleri belirlenmiştir. Asıl metaller modellenen kaynak telleri ile bir birine birleştirilmiş ve her bir analiz sonunda ortaya çıkan gerilmeler farklılık göstermiştir. Isıl genleşme katsayısından dolayı ortaya çıkan bu farklılıklar kaynak işlemi esnasında kaynak telinin mekaniksel verilerinin oluşan kalıntı gerilmeler üzerinde etkisi olduğunu ortaya koymaktadır. Analiz sonuçları gerilmelerin kaynak dolgusu etrafında yoğunlaştığını göstermektedir (Şekil 18).

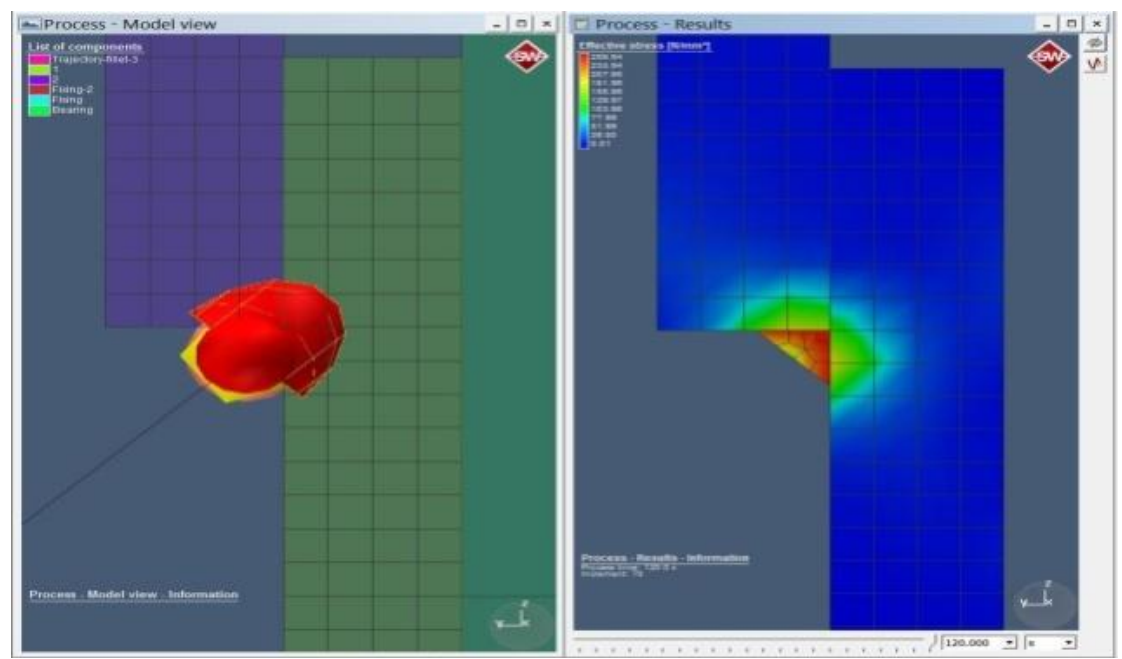

Şekil 18. Gerilme yoğunlaşması

Aynı zamanda bu gerilme değerleri asıl metalin akma sınırın (DIN 1.0037, Re=230 MPa) üstünde olduğu görülmektedir. Fakat yukarıda ki şekilde gerilmelerin yoğunlaştığı bölgenin aslında birleştirme işlemini yapan kaynak dolgusu olduğu görülmektedir. Kaynak teli üreticisi olan firmaların sunmuş olduğu bazı kaynak telleri için mekanik özellikler Tablo 3 de ki gibidir.[1-2]

Tablo 3. Kaynak telleri mekanik özellikleri

\begin{tabular}{|l|c|c|}
\hline & ASKAYNAK( AS SG3 ) & OERLIKON(MG 150 ) \\
\hline AKMA GERİLMESİ (Mpa) & 470 & 470 \\
\hline ÇEKME GERİLMESİ (Mpa) & 570 & 550 \\
\hline ŞEKİL DEĞİŞTİRME (\%) & 25 & 24 \\
\hline
\end{tabular}

Şekil incelendiği zaman kaynak dolgusu için ortalama akma sınırı 470 MPa olarak kabul edilebilir. Tekrar analiz sonuçları incelendiğin de kaynak dolgusu dışında kalan alanlarda maksimum kalıntı gerilmeler 50 - $60 \mathrm{MPa}$ civarında çıkmaktadır. Bu sonuçlar göz önünde bulundurulduğunda kaynak dolgusu için emniyet katsayısı minimum 1.5, asıl metal için emniyet katsayısı 3.8 çıkmaktadır.

Analiz modeli kaynak işlemi sonucunda oluşabilecek kalıntı gerilmeler hakkında bilgi vermektedir. Fakat gerçekte kaynak işlemi esnasında ortaya çıkan kalıntı gerilmeler teknisyenin hızına, ortam sıcaklığına, kaynak dokusunun homojen dağılmasına, hava kirliliğine, malzemenin homojenliğine v.b. birçok parametre ile doğrudan ilişkilidir. 


\section{Sonuç}

Yapılan çalışma neticesinde aşağıdaki sonuçlara ulaşılmıştır:

1. Isıl genleşme katsayısı kaynak işlemi sonucunda ortaya çıkan kalıntı gerilmelerde etkin rol oynamaktadır. \%1 - \%3 farklı olan 1sıl genleşme katsayıları çıkan kalıntı gerilme sonuçlarında \%5 $\% 10$ kadar değişiklik yapmaktadır,

2- Tasarım esnasında mukavemet hesaplarına kalıntı gerilme ile oluşan gerilmelerin de dâhil edilmesi ileride doğabilecek problemlerin önüne geçebilecektir,

3- Kaynak işlemi esnasında kalıntı gerilmeler daha çok kaynak dolgusu etrafında yoğunlaşmaktadır,

4- Kaynak işlemi esnasında oluşan kalıntı gerilmeler kritik değerlere ulaşması durumunda bu kalıntı gerilmelerin yok edilmesi ya da minimize edilmesi için parçalara gerilim giderme işlemleri uygulanmalıdır,

5- Kaynak işlemi esnasında oluşan kalıntı gerilmeler malzemelerin emniyet katsayıları üzerinde etkin rol oynamaktadır.

\section{Teşekkür}

Bu makale Murat ASLAN'ın yüksek lisans tezinden türetilmiştir.

\section{Kaynaklar}

[1] Subaşı M., Karataş Ç. "AISI 4140 Çeliğinde Elde Edilen Farklı Sertliklerin Kalıntı Gerilmeler Üzerindeki Etkisinin Araştırılması", Politeknik Degisi 2011 Cilt:14 Sayı: 4 s. 289 - 295.

[2] Kara S., Korkut M.H., "Zırhlı Muhabere Araçlarında Kullanılan Zırh Plakalarında Kaynak Sonrası Isıl İşlemin Birleşim Mukavemetine Etkisinin Araştırılmamı”, Savunma Bilimleri Dergisi 2012 Cilt:11 Say1 : 2 s.159-171.

[3] Bouhelier C., Barbarian P., Deville P. "Vibratory Stress Relief of Welded Parts", ASTM STP 999.

[4] Zhao X.C., Zhang Y.D., Zhang H.W. and Wu Q. "simulation of vibrationstress relief after weldıng based on fem "Acta Metall. Sin.(Engl.Lett.), Vol.21 No.4 pp289-294

[5] Grum J., Bozic S., Zupancic M., "Infuluence of quenching process parameters on residual stresses in steel", Journal of Materials Processing Technology, 2001 Vol.114 pp. 57-70.

[6] Capriccioli A., Frosi P. "Multipurpose ANSYS FE procedure for welding processes simulation", Fusion Engineering and Design 2009 Vol.48 pp. 123-137.

[7] Sih G. C., Strain energy density factor applied to mixed mode crack problems, International Journal of Fracture Mechanics, 1974 Vol. 10, pp. 305-321.

[8] Martinsson J., "Fatigue assessment of complex welded steel structures", Doctoral Thesis, Dept. of Aeronautical and Vehicle Engineering, KTH, Sweden 2005, Vol. 23, pp. 176-188.

[9] Sun M.C., Sun Y.H., Wang R.K. "Vibratory stress relieving of welded sheet steel of low alloy high strength steel "Materials Letters 2004 Vol: 58 pp.1396- 1399

[10] Finch D. and Burdekin F. M., Effect of welding residual stress on significance of defects in various types of welded joints, Engineering Fracture Mechanics, 1992 Vol. 41, No.5, pp.721735. 